\title{
Nonlinear FE Model for RC Shear Walls Based on Multi-layer Shell Element and Microplane Constitutive Model
}

\author{
Z. W. Miao ${ }^{1}$, X. Z. Lu ${ }^{1 *}$, J. J. Jiang ${ }^{1}$, L. P. Ye ${ }^{1}$ \\ ${ }^{1}$ Department of Civil Engineering, Tsinghua University, Beijing, 100084 China \\ Email: luxz@tsinghua.edu.cn
}

\begin{abstract}
Nonlinear simulations for structures under disasters have been widely focused on in recent years. However, precise modeling for the nonlinear behavior of reinforced concrete (RC) shear walls, which are the major lateral-force-resistant structural member in high-rise buildings, still has not been successfully solved. In this paper, based on the principles of composite material mechanics, a multi-layer shell element model is proposed to simulate the coupled in-plane/out-plane bending and the coupled in-plane bending-shear nonlinear behaviors of RC shear wall. The multi-layer shell element is made up of many layers with different thickness. And different material models (concrete or rebar) are assigned to various layers so that the structural performance of the shear wall can be directly connected with the material constitutive law. And besides the traditional elasto-plastic-fracture constitutive model for concrete, which is efficient but does not give satisfying performance for concrete under complicated stress condition, a novel concrete constitutive model, referred as microplane model, which is originally proposed by Bazant et al., is developed to provide a better simulation for concrete in shear wall under complicated stress conditions and stress histories. Three walls under static push-over load and cyclic load were analyzed with the proposed shear wall model for demonstration. The simulation results show that the multi-layer shell elements can correctly simulate the coupled in-plane/out-plane bending failure for tall walls and the coupled in-plane bending-shear failure for short walls. And with microplane concrete constitutive law, the cycle behavior and the damage accumulation of shear wall can be precisely modeled, which is very important for the performance-based design of structures under disaster loads.
\end{abstract}

Keywords: shear wall, nonlinear analysis, microplane, finite element, multi-layer shell element

\section{INTRODUCTION:}

Nonlinear simulations for structures under disasters have been widely focused on in recent years. However, precise modeling for the nonlinear behavior of reinforced concrete (RC) shear walls, which are the major lateral-force-resistant structural member in high-rise buildings, still has not been successfully solved. As the cross section of the shear wall member is much bigger than that of the beam and column member, its deformation behavior under the lateral load is more complicated and the research has focused on the nonlinear analysis model for shear wall at home and abroad until now. In this paper, based on the principles of composite material mechanics, a multi-layer shell element model is proposed to simulate the coupled in-plane/out-plane bending or the coupled in-plane bending-shear nonlinear behaviors of RC shear wall. At the element level, the model uses the shell element that is made up of multiple layers with different thickness and different material models (concrete or rebar) are assigned to various layers. Since the model relates the nonlinear behaviors of the shear wall element to the constitutive relations of concrete and steel directly, it has many advantages in the description of the actual complicated nonlinear behaviors. In the nonlinear analysis for the concrete structures, the constitutive relation of the concrete has great effect on the analysis results. Although the traditional elasto-plastic-fracture constitutive model for concrete is efficient, it does not give satisfying performance for concrete under complicated stress condition. So at the material constitution level, a novel concrete constitutive model, referred as microplane model, which is originally proposed by Bazant et al., is developed to provide a better simulation for concrete in shear wall under complicated stress conditions 
and stress histories. In order to validate the capacity of the proposed shear wall model, three shear walls with different nonlinear behaviors under given load cases were taken as examples. Pushover analysis and static cyclic loading analysis were carried out on these shear walls with the proposed shear wall model to illustrate the capacity of the proposed model.

\section{MULTI-LAYER SHELL ELEMENT}

The proposed multi-layer shell element is based on the principles of composite material mechanics and it can simulate the coupled in-plane/out-plane bending and the coupled in-plane bending-shear nonlinear behaviors of RC shear wall. Basic principles of multi-layer shell element are illustrated by Figure 1. The shell element is made up of many layers with different thickness. And different material properties are assigned to various layers. This means that the rebars are smeared into one layer or more. During the finite element calculation, the axial strain and curvature of the middle layer can be obtained in one element. Then according to the assumption that plane remains plane, the strains and the curvatures of the other layers can be calculated. And then the corresponding stress will be calculated through the constitutive relations of the material assigned to the layer. From the above principles, it is seen that the structural performance of the shear wall can be directly connected with the material constitutive law.

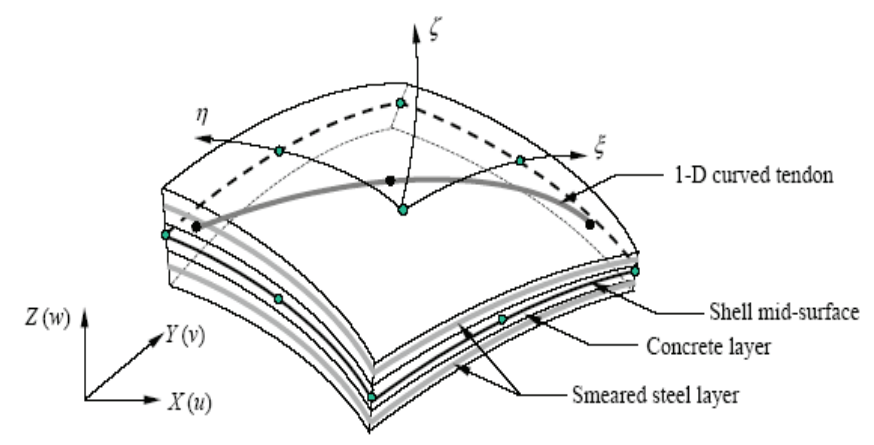

Figure 1: Multi-layer shell element
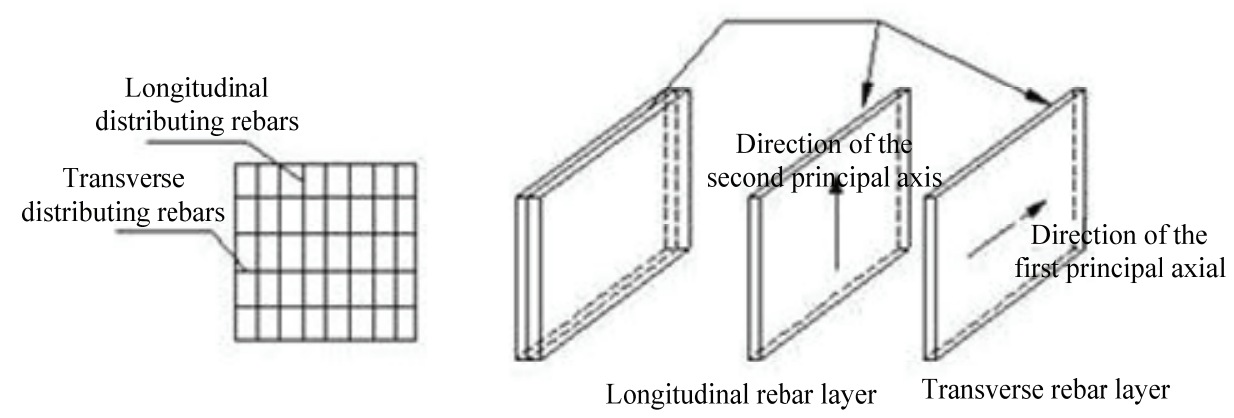

Figure 2: Settings of the rebar layers

The constitutive model of the rebars is set as the perfect elasto-plastic model. Because the rebars in different directions are smeared into one layer, so if the ratios of the amounts of the distributing rebars to the concrete in the longitudinal direction and transverse direction are the same, the rebar layer can be set as isotropic. But if the ratios in the two directions are different, the rebar layer should be set as orthotropic with two principal axes as shown in Figure 2. And in different principal axis, the stiffness is set different according to the ratio of the amount of rebars to concrete to simulate longitudinal rebars and transverse rebars respectively. The constitutive model of the concrete is the microplane model which will be illuminated in detail in the next section. 
Since the model relates the nonlinear behaviors of the shear wall element to the constitutive relations of concrete and steel directly, it has many advantages in the description of the actual complicated nonlinear behaviors as compared with the existing equivalent-beam model, equivalent-truss model and the multi-component-in-parallel model for shear wall ${ }^{[1]}$.

\section{MICROPLANE CONSTITUTIVE MODEL FOR CONCRETE}

Concrete is a kind of brittle-plastic material and its relation between the stress and strain under the multi-axial loads is very complicated, so in the nonlinear analysis for the concrete structures, the constitutive model of the concrete has great effect on the analysis results. Usually the precision and the validity of the shear wall model is mainly decided by the precision and the validity of the constitutive model for concrete. The traditional elasto-plastic-fracture constitutive models for concrete are macroscopic models. Although great success has been reached in the past, the macroscopic models now seem to have entered a period of diminishing returns, in which a great effort yields only little improvement ${ }^{[2]}$. When the concrete is under complicated stress condition, these models often can't give satisfying performance for the concrete material. So at the material constitution level, a novel concrete constitutive model, referred as micro-plane model, which is originally proposed by Bazant et al. ${ }^{[5]}$, is introduced in the proposed shear wall model and this is achieved by developing the subroutine based on MSC.Marc.

As one kind of the micromechanics models, microplane model considers the microstructure of the material. In the microplane model, a set of planes of any orientations in the material microstructure called as the microplane are referred. And the constitutive law is formulated in terms of vectors rather than tensors, as a relation between the stress and strain components on these microplanes. By integrating over the all the spatial directions, the microplane model can satisfy the tensor invariant requirement automatically on the macroscopic and conceptual simplicity is achieved. Due to the research work of P. Bazant et al. ${ }^{[2,3,4,5]}$, there have been much progress on microplane model during the last 20 years. In the first version, the microplane model of concrete was only devised for tensile fracturing, but now it has been updated to the fourth version which can characterize the complicated nonlinear triaxial behavior as well as the deformation behavior under the cyclic load. The results of the numerical analysis for basic loading types with the microplane model have been compared with many actual test results and it is shown that microplane models can characterize the responses of concrete under different loading types ${ }^{[2]}$.

\section{DEMONSTRATION CASES}

In order to validate the capacity of the proposed shear wall model, three shear walls were selected as the demonstration models. Pushover analysis and static cyclic loading analysis were carried out on these shear walls with the proposed shear wall model.

For the shear wall, the lengths in two directions in the wall plane are both much larger than the thickness of the wall. This is much different from the beam and column members, and it will lead to bending deformations as well as shear deformations which usually can't be neglected at the same time when the wall is under lateral load in plane. These shear deformations in the wall plane have an important effect on the failure type of the wall and this complicated behavior causes the nonlinear analysis of the shear wall become much more difficult than the beam element directly. Because the shear span ratio of the wall is a main factor which affects the shear deformation behavior, case 1 and case 2 will simulate the coupled in-plane bending-shear nonlinear behaviors of RC shear wall with different shear span ratios respectively. And case 3 simulates the out-plane bending behaviors of RC shear wall. Figure 3 shows the finite element model in case 1 , and the finite element model for case 2 and case 3 are similar to case 1 . 

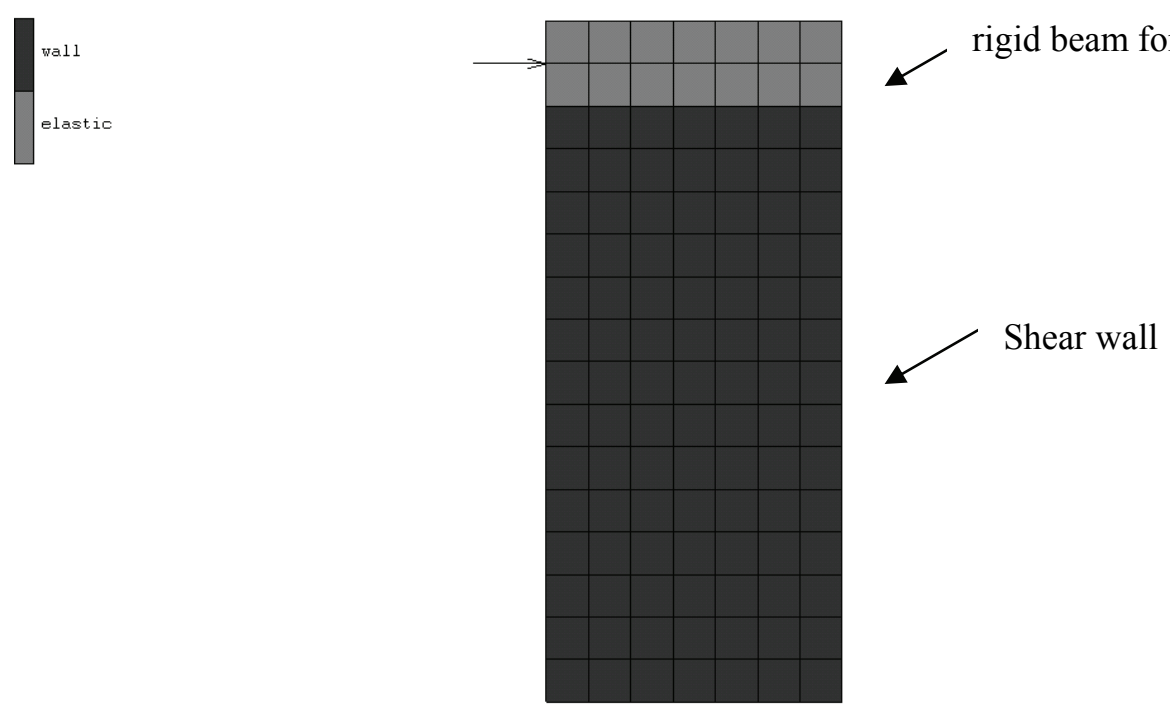

Figure 3: Finite element model in case 1

\section{Case 1:}

The shear span ratio of the shear wall in this case is 2 . For pushover analysis, the in-plane lateral load increased by step is only applied at the top of the wall. Besides, static cyclic loading process is also analyzed. In both the two analysis, the vertical load with the axial force ratio of 0.2 is applied in advance at the top of the wall. The load-displacement curve for pushover is plotted in Figure 4. Besides, the contour of the principal major strain at the state with the peak load in pushover is plotted in Figure 6.

From Figure 4, it can be seen that the utmost loading capacity of the shear wall is about $170 \mathrm{kN}$ with the displacement of about $7 \mathrm{~mm}$. And Figure 6 shows that at this time, quite a lot of concrete elements at the bottom had cracked and most tensile rebars had yielded. After that, as the crack expanded, the compressive area was getting smaller and smaller, which caused the loading capacity drop. It can be concluded that the failure type of the wall in this case is mainly in-plane bending failure and shear deformation doesn't play an important part in the response of the shear wall.

Displacement of the shear wall along the height at different stages in pushover is shown in Figure 5, indicating that the shape of lateral displacement is of bending type. So the deformation behavior of shear wall structure is clearly illustrated here.

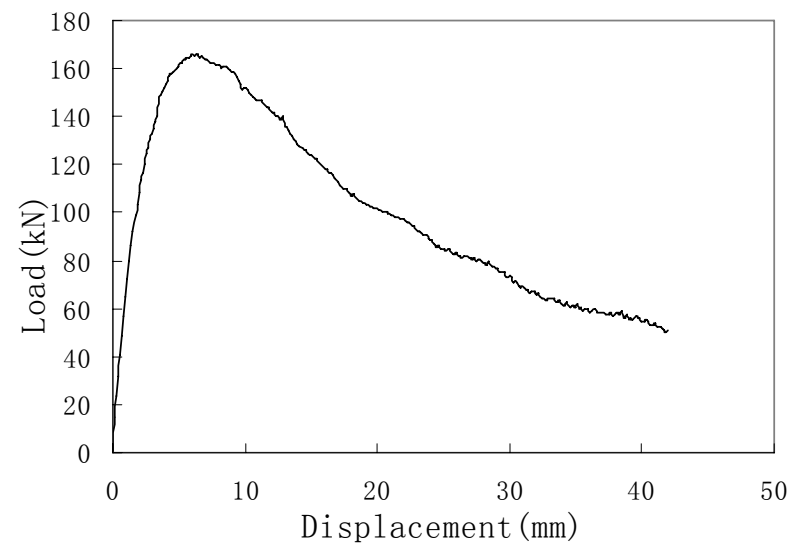

Figure 4: Load-Displacement curve for pushover

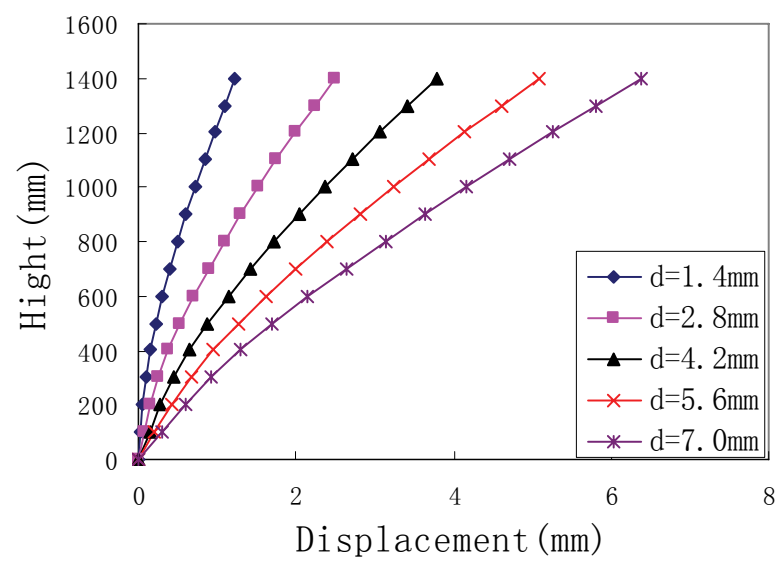

Figure 5: Displacement along the height at different stages in pushover 

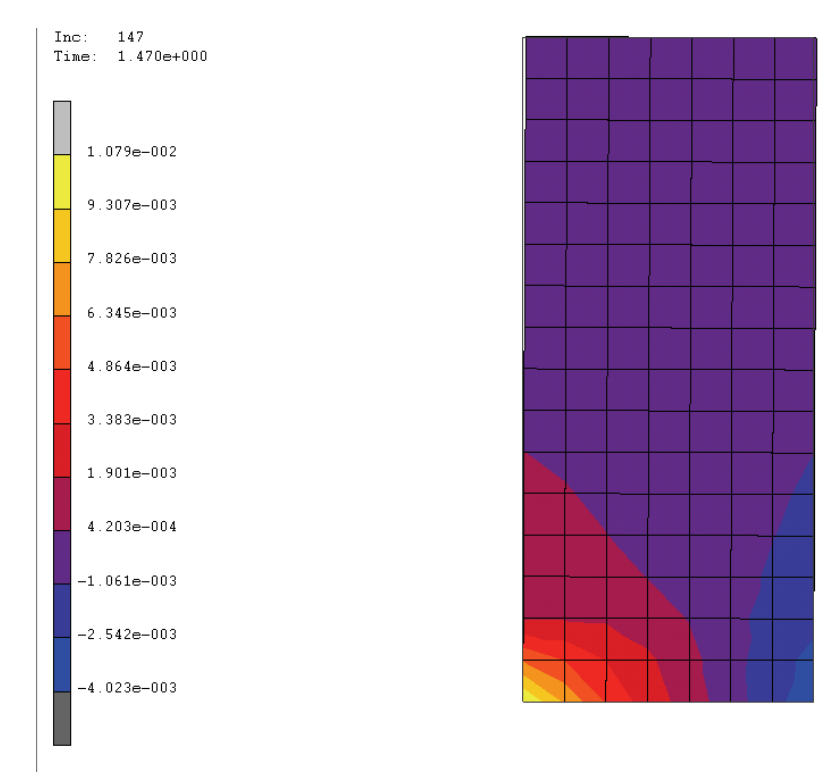

Figure 6: Contour of the principal major strain at the state with the peak load in pushover

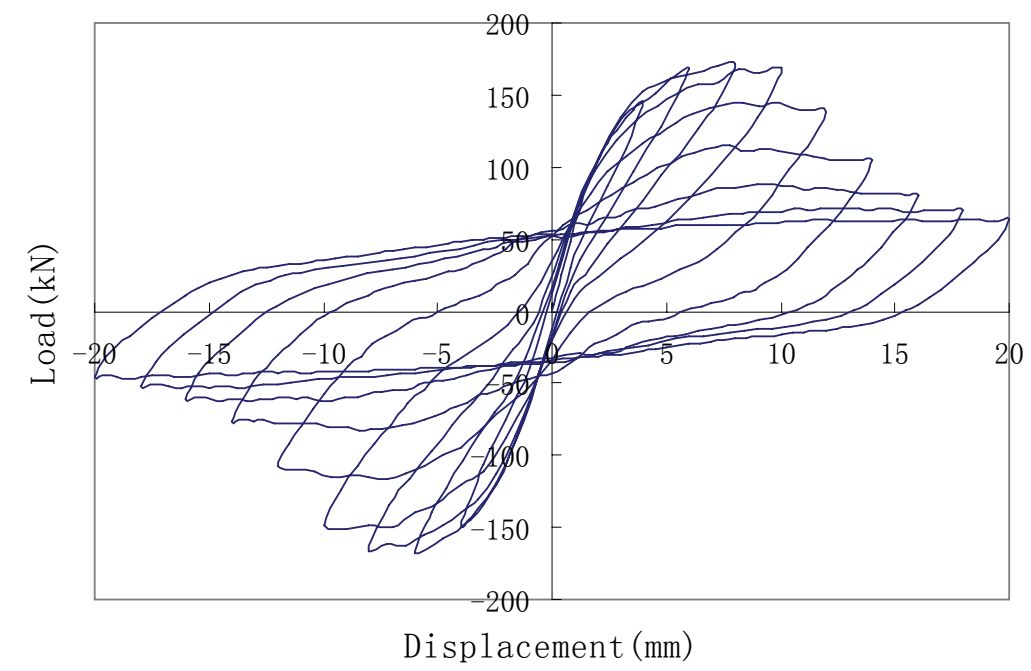

Figure 7: Load-Displacement curve for cyclic loading

Load-Displacement curve for cyclic loading is plotted in Figure 7 and the pinch effect is shown in it. This reflects the actual response characteristics of the shear wall under cyclic load clearly. Besides, exterior envelope of the load-displacement curve has entered the softening part, which indicates that the microplane model can simulate the damage accumulation of shear wall during the cyclic loading process precisely. This is very important for the performance-based design of structures under disaster loads.

\section{Case 2:}

The shear span ratio of the shear wall in this case is 1 , therefore this wall belongs to the type of short wall and the in-plane shear failure always occurs in this type of walls.

The load-displacement curve is shown in Figure 8 and the curve of the same relation in case 1 is also shown in Figure 8 for a comparison. It can be seen that the stiffness and the loading capacity of the wall in case 2 are much larger than that in case 1 because the shear span ratio has affected the response characteristic of the shear wall under the lateral load. Similarly to case 1, the contour of the principal major strain at the state with the peak load is plotted in Figure 9 to show more details about the failure type of the wall. In fact, Figure 9 shows that at state of the maximum loading capacity, a compressive column had formed in the diagonal direction of the wall. After that, the concrete of the diagonal compressive column was crushed and quitted the loading gradually, which caused the loading capacity of the wall drop. But this process is more brittle than the descending process in case 1. This can be proved by comparing the 
descending part of the two curves in Figure 8. This is a typical in-plane shear failure process of shear wall. Obviously, shear deformation plays an important part in the response of the shear wall in this case and the shear failure process has much more brittleness than the bending failure process.

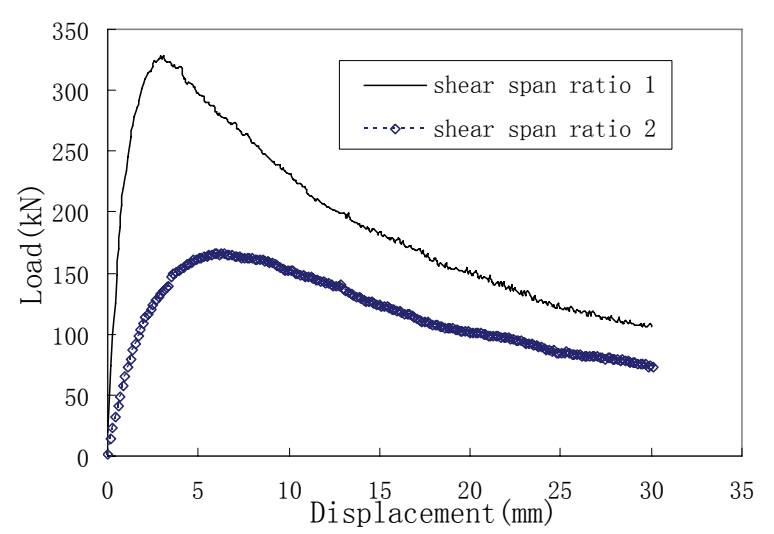

Figure 8: Load-Displacement curve for pushover

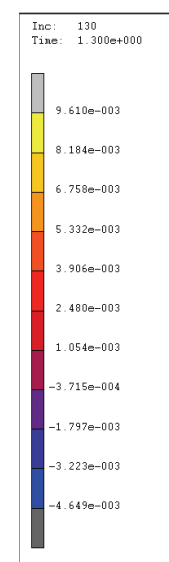

Figure 9: Contour of the principal major strain at the state with the peak load in pushover.

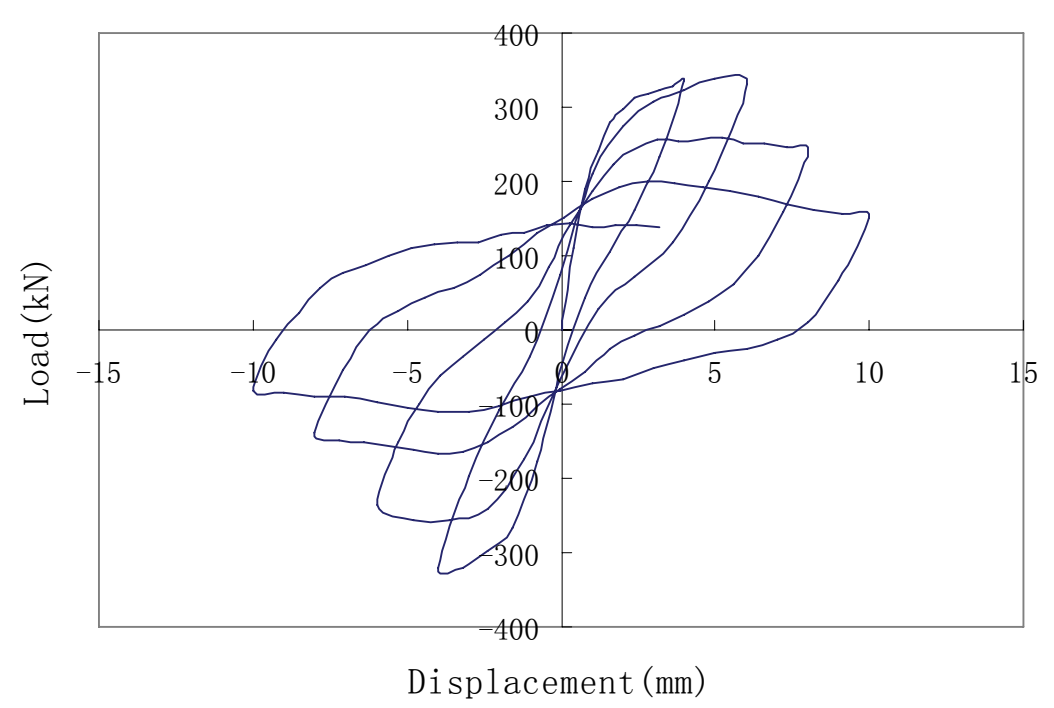

Figure 10: Load-Displacement curve for cyclic loading

In Figure 10, the pinch effect can still be seen in the load-displacement curve for cyclic loading. And similarly to Figure 7, exterior envelope of the load-displacement curve has entered the softening part because of the damage accumulation of shear wall during the cyclic loading process. But the exterior envelope of the load-displacement curve in case 2 is steeper than case 1 because the shear failure process has much more brittleness than the bending failure process

\section{Case 3:}

In the actual shear wall structures, the shear walls are laid in both longitudinal and transverse directions. When the lateral load is applied to structure in one direction, the response of the wall with the plane in the same direction will present the coupled in-plane bending-shear nonlinear behavior just as in the above case 1 and case 2. But the wall with the plane perpendicular to the loading direction will bend out of the loading plane and present the out-plane bending behavior. This must be considered in the finite element analysis for shear wall structures.

In case 3, the geometric model is the same as in case 1. To study the out-plane bending behavior of shear wall, the out-plane lateral load increased by step is applied at the top of the wall, and the vertical load with different axial force ratios is applied in advance at the top of the wall. 
Figure 11 shows the relation between the lateral load and the lateral displacement at the top of the wall under different axial forces studied. Because the thickness of the shear wall is much smaller than the height, the out-plane bending behavior of the shear wall is very similar to the bending behavior of the 1-D beam element. This can be proved from Figure 11.

Obviously, the program can obtain the softening out-plane bending behavior of the wall. Besides, the plot showing the relation between the maximum moment $\mathrm{M}_{\max }$ and corresponding axial force ratio in Figure 12, indicates accords with the existing theory ${ }^{[6]}$ as well. From these analysis results, it can be concluded that the proposed multi-layer shell element model with the microplane constitutive models for the concrete does well in simulating the out-plane bending behavior of the shear wall under different axial forces.

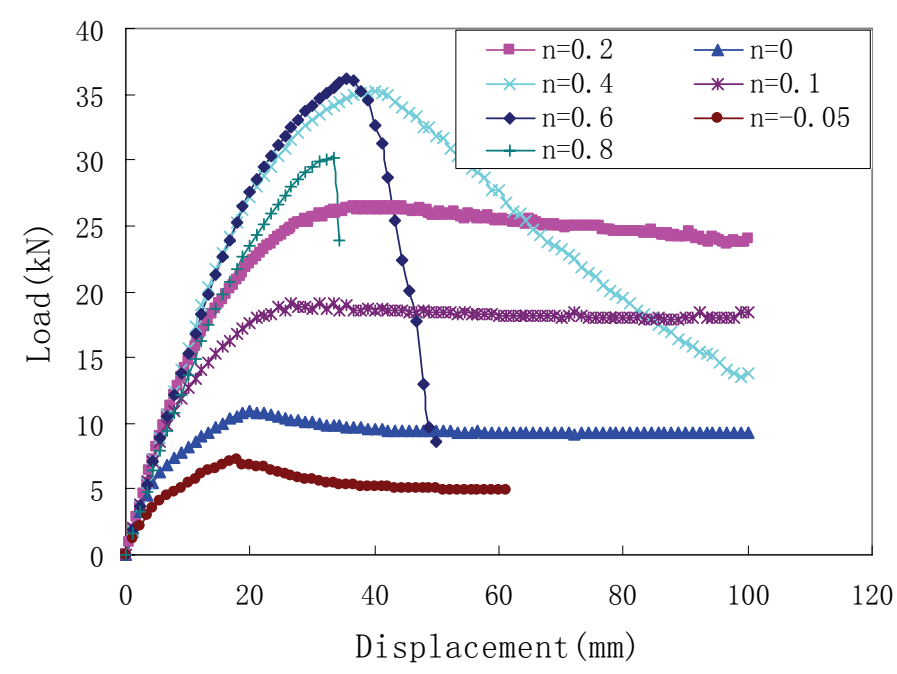

Figure 11: Load-Displacement curves under different axial force ratios in case 3

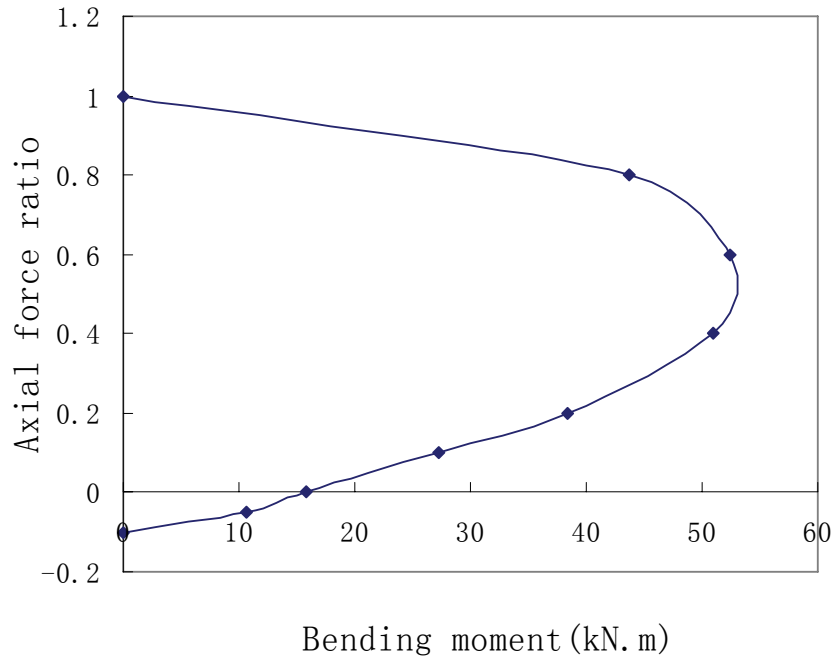

Figure 12: Relation between different axial force ratios and maximum bending moments

\section{CONCLUSION}

The proposed multi-layer shell element model based on the principles of composite material mechanics relates the nonlinear behaviors of the shear wall element to the constitutive relations of concrete and steel directly, and therefore it has many advantages in the description of the actual complicated nonlinear behaviors. And at the material constitution level, a novel concrete constitutive model, referred as micro-plane model is introduced to provide a better simulation for concrete in shear wall under complicated stress conditions and stress histories. The simulation results show that the multi-layer shell element model can correctly simulate the coupled in-plane/out-plane bending failure for tall walls and the coupled in-plane bending-shear failure for short walls. And with micro-plane concrete constitutive law, the cycle behavior and the damage accumulation of shear wall can be precisely modeled, which is very important for the performance-based design of structures under disaster loads.

\section{ACKNOWLEDGEMENT}

The authors are grateful for the financial support received from the Specialized Research Fund for the Doctoral Program of Higher Education, No.20040003095.

\section{REFERENCES}

1. Jiang JJ, Lu XZ, Ye LP. Finite Elelement Analysis of Concrete Structures. Tsinghua University Press, Beijing, China, 2005.

2. Bazant ZP, Caner FC, Carol I, Adley MD, Akers SA. Microplane model M4 for concrete. I: formulation with work-conjugate deviatoric stress. Journal of Engineering Mechanics, 2000, 126(9): 944-953.

3. Bazant ZP, Xiang YY, Prat PC. Microplane model for concrete. I: stress-strain boundaries and finite strain. Journal of Engineering Mechanics, 1996, 122(3): 245-254. 
4. Bazant ZP, Prat PC. Microplane model for brittle-plastic material. I: theory. Journal of Engineering Mechanics, 1988, 114(10): 1672-1688.

5. Bazant ZP, Oh BH. Microplane model for progressive fracture of concrete and rock. Journal of Engineering Mechanics, 1985, 111(4): 559-582.

6. Ye LP. Concrete Structures. Tsinghua University Press, Beijing, China, 2002. 